\title{
Numerical and Modeling Analysis of Fluid Flow and Heat Transfer of Liquid Steel in a Tundish with Different Flow Control Devices
}

\author{
R. D. MORALES, S. LÓPEZ-RAMIREZ,") J. PALAFOX-RAMOS and D. ZACHARIAS ${ }^{2)}$
}

Department of Metallurgy, Instituto Politécnico Nacional-E.S.I.Q.I.E., Apdo. Postal 75-874, CP 07300, Mexico D.F., E-mail: rodolfo(aragnatela.net.mx 1 1) Departments of Chemical Engineering and Metallurgy, Instituto Politécnico NacionalE.S.I.Q.I.E., Apdo. Postal 75-874, CP 07300, México D.F. $\quad$ 2) FOSECO INC. 20200 Sheldon Road Cleveland, OH, USA.

(Received on October 16, 1998; accepted in final form on February 2, 1999)

\begin{abstract}
Fluid flow and heat transfer of liquid steel in a two-strand tundish of a slab caster were analyzed using water modeling and numerical techniques. Three cases were considered: A bare tundish, a tundish equipped with a pair of weirs and a pair of baffles (arrangement $W \& B$ ) and a tundish equipped with a turbulence inhibitor and a pair of baffles (arrangement $\mathrm{T} \mid \& \mathrm{~B}$ ). The water modeling, under isothermal conditions, indicated the existence of a strong bypass-flow for the bare tundish and the W\&B arrangement while the $T I \& B$ arrangement reported a longer minimum residence time and higher plug flow characteristics. Numerical results verified the trend mentioned with the water model. The numerical study showed also that cold and hot steel affected considerably the flow patterns of steel due to the existence of buoyancy forces. In the case of a step-input of cold steel, bypass-flow was intensified for the bare tundish and the tundish with a W\&B arrangement. When a step input of hot steel is introduced into the system buoyancy forces make the steel to flow preferentially near the free surface.

The tundish with a $T / \& B$ arrangement showed the best flow characteristics with not splashing and negligible turbulence. This arrangement shows a slower response to thermal disturbs coming from the input making the tundish a less exposed reactor to the temperature changes and the consequent changes in flow patterns usually found in real casting operations.
\end{abstract}

KEY WORDS: tundish; fluid flow; numerical; heat transfer; turbulence inhibitor; weirs; baffles; water modeling; buoyancy forces; cold steel; hot steel.

\section{Introduction}

There have been many researches reported on the benefits of flow control devices (FCD) of liquid steel in tundishes. ${ }^{1-5)}$ All of them were looking at longer residence times of fluid in the reactor through increases in the plug flow pattern aiming at longer times for flotation of the non-metallic inclusions. Dams and weirs were some of the first FCD employed to control steel flow. Although some benefits in flow control were clearly observable it was soon realized the formation of large dead volumes in the back zones of these FCD. Besides, the importance of FCD designs on control of liquid steel in tundishes has been reported somewhere else. ${ }^{6)}$

More recently efforts have been carried out aiming at decreasing heavy splashes during start up operations of casting sequences, ladle change operations and wear rate of tundish refractories. Elimination of the pick up of oxygen and nitrogen from surrounding air through the turbulent zone, formed near the incoming liquid jet delivered by the submerged entry nozzle (SEN), has been another objective. All this has been successfully reached using a new kind of FCD devices better known as turbulence inhibitors. ${ }^{78)}$ These devices are a kind of an impact pad with lips and interiors with right angles or rounded ones and squared or rounded cross sections. The high turbulence of the fluid promoted by the liquid jet is inhibited by its impact with the bottom and lips of the inhibitor provoking an upward and softer flow toward the slag phase. In this sense the authors have reported the great benefits on flow control and steel cleanliness obtained by using a turbulence inhibitor (TI) combined with a pair of baffles in a four strands tundish of a bloom caster.9) According to plant trials this arrangement exceeds, considerably, the overall performance of the tundish as compared with another arrangement consisting in two pairs of baffles and an impact pad. In spite of the merits of TI to control steel flow and to decrease heavy splashes, fluid turbulence and pick up of gases some questions remain still unanswered particularly in regarding the thermal dynamics of steel in the tundish. This is why is consequent to ask for its effects on the thermal behavior. This is particularly crucial since temperature control is one of the most important issues in continuous casting.

The aim of the present study is to analyze the relationship between the design of FCD, fluid flow behavior and heat transfer in a tundish subjected to different steel input temperatures. This analysis will allow someone to evaluate the influence of two different 

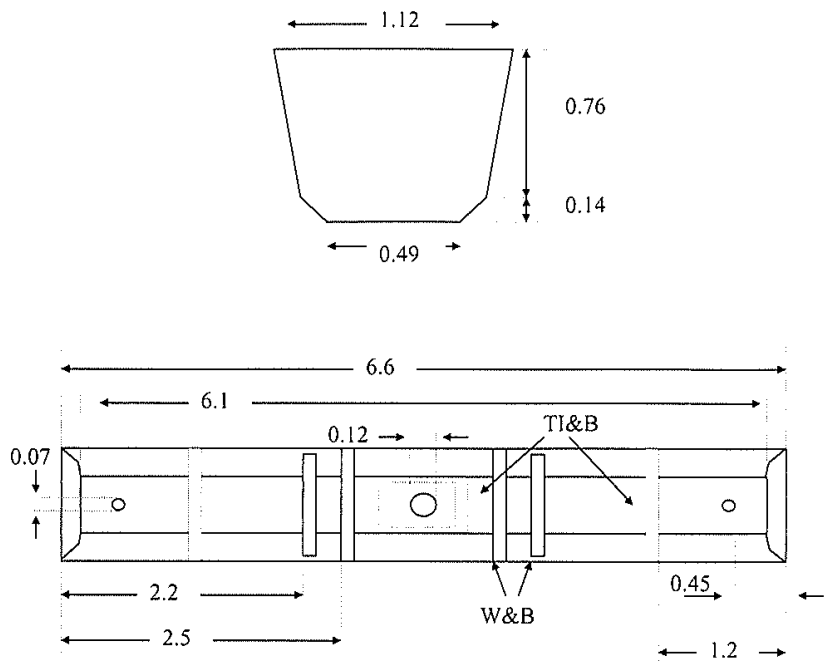

Fig. 1. Geometric dimensions of the industrial tundish under study.
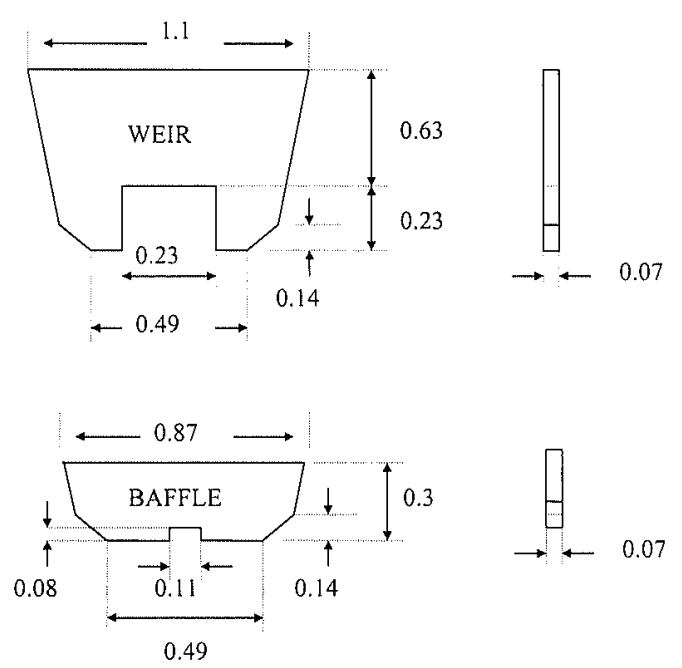

Fig. 2. Geometric characteristics of the weir and baffe employed in the $W \& B$ arrangement.

FCD arrangements, with emphasis on the employment of a TI, on the thermal response of the output steel temperature.

\section{Description of the Industrial Tundish}

The selected tundish for the present analysis belongs to a Company in Brazil. The physical dimensions of this tundish are shown in Fig. 1. This two-strand tundish corresponds to a slab caster and is equipped with a pair of baffles and another pair of weirs located as indicated in the same Fig. 1 (arrangement W\&B). The dimensions of these FCD are presented in Fig. 2. On the other hand, another arrangement of FCD consists in a pair of baffles and TI (arrangement TI\&B) whose physical dimensions are shown in Fig. 3(a) and 3(b) respectively. The locations of these later FCD in the industrial tundish are indicated also in Fig. 1.

\section{Experimental Procedure}

A water model of this tundish was built using a $1 / 3$ scale (see Fig. 1) following as a scaling up criterion the
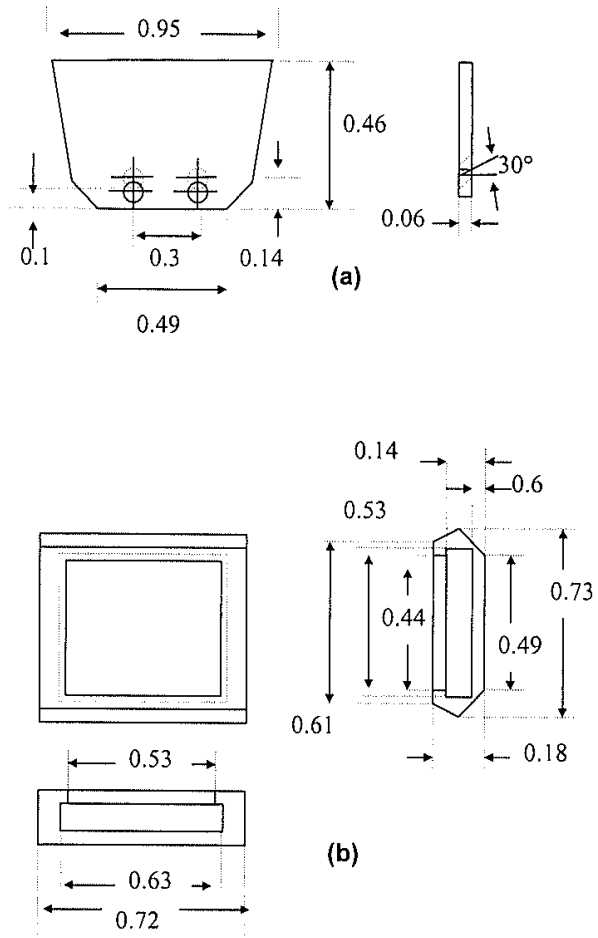

Fig. 3. Gcometric characteristics of the baffle (a) and the lurbulence inhibitor (b) employed in the TI\&B arrangement.

Froude number. ${ }^{10)}$ Red dye was employed as tracer to characterize the curves for Residence Time Distribution (RTD) for arrangements $\mathrm{B} \& \mathrm{~W}$ and TI\&B as well as the bare tundish following well established techniques. ${ }^{11}$ All experiments were performed at constant room temperature of $298 \mathrm{~K}$ under steady state conditions. The steel flow rate employed in this study was kept constant and equal to 5.34 ton $/ \mathrm{min}$. This flow rate is equivalent to $8.156 \times 10^{-4} \mathrm{~m}^{3} / \mathrm{sec}$ in the water model according to Froude's criterion.

\section{Numerical Model}

\subsection{Fundamental Equations}

The mathematical model consists in the simultaneous solution of the continuity, momentum transfer and energy transfer equations under turbulent conditions. They were solved together with the turbulence kinetic energy and dissipation rate of the turbulence kinetic energy equations using the well known $k-\varepsilon$ model for turbulent flows. ${ }^{12)}$ These equations take the following forms:

Mass: $\quad \frac{\partial \rho}{\partial t}+\nabla \cdot(\rho u)=0$

Momentum:

$$
\frac{\partial(\rho u)}{\partial t}+u \cdot \nabla(\rho u)=-\nabla P+\nabla \cdot\left(\left(\mu_{1}+\mu_{t}\right) \nabla u\right)+F_{\mathrm{B}}
$$

Energy: $\frac{\partial(\rho h)}{\partial t}+u \cdot \nabla(\rho h)=\nabla\left(\left(\frac{\kappa}{C_{\mathrm{p}}}+\frac{\mu_{\mathrm{t}}}{\sigma_{\mathrm{h}}}\right) \nabla h\right)$

$F_{\mathrm{B}}$ represents the buoyancy force, given by

$$
F_{\mathrm{B}}=\rho g\left(1-\beta\left(T-T_{\text {ref }}\right)\right)
$$




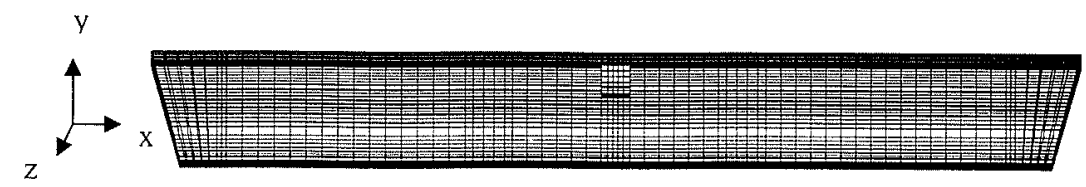

Fig. 4. Mesh of the physical domain to simulate heal and fluid flow in the tundish.

This later Equation expresses that as a fluid element decreases in temperature it experiences a greater force in the direction of gravity. Buoyancy force term is the coupling element of the momentum and energy equations. In those equations $u$ is the averaged velocity vector and $h$ is steel enthalpy in the $3 \mathrm{D}$ generalized space domain. Additionally $\rho, \beta$ and $\kappa$ are density, thermal expansion coefficient and thermal conductivity of steel respectively. Meanwhile, $\mu_{1}$ and $\mu_{\mathrm{t}}$ are molecular and turbulent viscosity of fluid respectively and the sum of both quantities is known as the effective viscosity of fluid, $\mu_{\text {eff }}$. The turbulent viscosity is calculated through its relationship with the kinetic energy and its dissipation rate. ${ }^{12)}$ The turbulent kinetic energy equation, $k$, and its dissipation rate, $\varepsilon$, are given by:

$$
\begin{gathered}
\frac{\partial}{\partial t}(\rho k)+\nabla \cdot(\rho u k)=\nabla \cdot\left(\Gamma_{k} \nabla k\right)+G-\rho \varepsilon \\
\frac{\partial(\rho \varepsilon)}{\partial t}+\nabla \cdot(\rho u \varepsilon)=\nabla \cdot\left(\Gamma_{\varepsilon} \nabla \varepsilon\right)+\frac{\varepsilon}{k}\left(C_{1} G-C_{2} \rho \varepsilon\right)
\end{gathered}
$$

Where $\Gamma_{k}$ and $\Gamma_{\varepsilon}$ are diffusion coefficients for the turbulent kinetic energy and its dissipation rate. ${ }^{12,13}$ ) Other symbols have their usual meaning.

Values for $C_{\mu}, C_{1}, C_{2}, \sigma_{k}$ and $\sigma_{\varepsilon}$ are $0.09,1.44,1.92$, 1.0 and 1.3 respectively, turbulent Prandtl number, $\sigma_{\mathrm{h}}$ (Eq. (3)) has a value of $0.9 .^{12)}$ Generation term, $G$, in Eqs. (6) and (7) can be consulted somewhere else. ${ }^{13}$ )

\subsection{Initial and Boundary Conditions}

A half of the tundish shown in Fig. 1, from the symmetric central-longitudinal plane was chosen for this mathematical analysis. This domain was divided in 38000 cells making a finer mesh in the zone of the incoming liquid stream just to study in more detail the effects of the TI. Figure 4 shows an overview of the mesh employed in the solution of the fluid flow and heat transfer equations.

At the SEN exit, the mean vertical velocity $\left(V_{\mathrm{m}}\right)$ was assumed to be uniform through its cross section and the other two velocity components were assumed to be zero. The turbulence kinetic energy, $k$, and its dissipation rate, $\varepsilon$, were assumed to be uniform also and calculated as proposed in Ref. 12).

Boundary conditions for momentum transfer at all solid surfaces including walls and bottom of tundish, surfaces of baffles and TI were those of non-slipping, zero normal velocity gradients at symmetry planes and frictionless conditions at the free surface of liquid steel. Similar boundary conditions were established for $k$ and $\varepsilon$. Near any solid surface including walls and bottom of tundish, baffles, weirs, TI and the side walls of SEN and tundish outlets nozzles the logarithmic law ${ }^{14)}$ was employed.
Table 1. Heat losses from the tundish.

\begin{tabular}{|c|c|c|c|}
\hline $\begin{array}{l}\text { Free surface of the } \\
\text { bath }\end{array}$ & Tundish bottom & $\begin{array}{c}\text { Vertical- } \\
\text { longitudinal walls }\end{array}$ & $\begin{array}{c}\text { Vertical-transversal } \\
\text { Walls }\end{array}$ \\
\hline $15000 \mathrm{~W} / \mathrm{m}^{2}$ & $1400 \mathrm{~W} / \mathrm{m}^{2}$ & $3200 \mathrm{~W} / \mathrm{m}^{2}$ & $3800 \mathrm{~W} / \mathrm{m}^{2}$ \\
\hline
\end{tabular}

Table 2. Physical propertics of liquid steel employed in the mathematical model

\begin{tabular}{|l|c|}
\hline Property & Liquid Steel at 1873 K \\
\hline Absolute viscosity & 0.005 \\
\hline Density & $7010+\left(\mathrm{T}-\mathrm{T}_{\text {nq }}\right)(-0.883)$ \\
\hline Surface tension & 1.7 \\
\hline Specific heat capacity & 750.0 \\
\hline Thermal conductiviy & 41.0 \\
\hline
\end{tabular}

Regarding the energy Equation, the boundary conditions include heat losses through the walls, bottom and free surface of fluid in the tundish. These heat fluxes were those already employed by the authors in another publication $^{15}$ and are reported in Table 1 . The physical properties of liquid steel employed in these simulations are reported in Table 2 .

Mathematical simulations of the process consisted in using a constant flow rate of steel from the ladle to the tundish equal to $5.34 \mathrm{ton} / \mathrm{min}$ at an initial temperature of I $840 \mathrm{~K}$ until reaching a steady state. Afterwards step input temperatures higher and lower than $1840 \mathrm{~K}$, by $15 \mathrm{~K}$, were introduced as initial conditions (1855 and $1825 \mathrm{~K}$ respectively) just to study the effects of the buoyancy force on the flow dynamics of the system, under unsteady state conditions, as influenced by the FCD arrangements.

To simulate the unsteady state conditions the flow and thermal fields under steady state conditions were employed as initial conditions in all cases including the bare tundish and the $W \& B$ and $T I \& B$ arrangements already presented in Figs. 1-3.

\subsection{Numerical Method}

The momentum, energy and turbulence Equations and all boundary conditions were rewritten for a computational domain, using body fitted coordinates, with a finite difference scheme in the 3D mesh shown in Fig. 4 and simultaneously solved by a numerical technique called PISO $^{16.17)}$ (Pressure Implicit with Splitting Operations). Since the enthalpy is very sensitive to tolerance set ups, this variable was chosen as an indicator of convergence establishing, for this purpose, a value of $1 \times 10^{-7}$. This criterion allowed tolerances in velocity vectors and their respective gradients of $1 \times 10^{-5}$.

This simulator was run in two workstations Silicon Graphics O2 with R-10000 processors at the Laboratory for Simulation of Metals Processing of IPN-ESIQIE, 
Department of Metallurgy.

\section{Results and Discussion}

\subsection{Water Modeling}

Figure 5 shows the RTD curves for the bare tundish, $\mathrm{B} \& \mathrm{~W}$ and TI\&B arrangements. In the first two cases it is observed the existence of bypass-flow conditions owing to flow malfunctions in the reactor. In the third case the RTD curve indicates a considerable improvement as compared with the precedent cases.

Just to compare the results shown in Fig. 5, the Table 3 shows the parameters derived from the analysis of the experimental data through established techniques. ${ }^{11)}$ Indeed, these values indicate a higher fraction of flow volume under a plug flow pattern for arrangement TI\&B

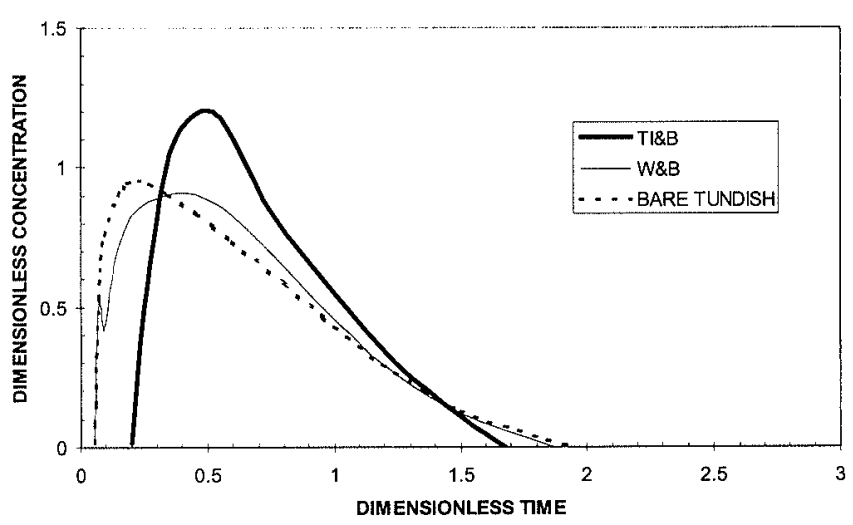

Fig. 5. Experimental RTD curves for a bare tundish, and a tundish with $W \& B$ and $T I \& B$ arrangements. than arrangement W\&B and, evidently, than the bare tundish.

\subsection{Numerical Model}

\subsubsection{Fluid Flow}

In this preliminary analysis the fluid flow and heat transfer results to be presented correspond only to the longitudinal-symmetric plane of the tundish. Fluid flow in a bare tundish and a tundish with $W \& B$ and TI\&B arrangements are shown in Figs. 6(a), 6(b) and 6(c) respectively under steady state conditions and an entering steel at $1840 \mathrm{~K}$.

The bare tundish shows heavy fluid mixing with high turbulence in the stream-entering zone and steel in the nearby zones presents a counter-flow because of the high momentum transfer promoted by the stream-jet. Flow velocity is higher in the bath surface than in the tundish bottom with exception of the zone located near the outlet.

The tundish with a W\&B arrangement shows a strong counter-flow of steel near the entering stream due to the presence of a weir. Between the weir and the baffle a recirculating flow is observed. A heavy bypass-flow can be observed through the holes of the weir and baffle

Table 3. Flow parameters derived from the water model.

\begin{tabular}{|l|c|c|c|}
\hline \multicolumn{1}{|c|}{ Parameter } & Bare tundish & $\begin{array}{l}\text { Arrangement } \\
\text { W\&B }\end{array}$ & $\begin{array}{l}\text { Arrangement } \\
\text { TI\&B }\end{array}$ \\
\hline Minimum residence time & 24.9 & 24.9 & 67.6 \\
\hline Peak concentration (\%) & 90.9 & 88.6 & 100.1 \\
\hline Peak concentration time & 57.5 & 75.0 & 110.0 \\
\hline Median residence time & 150.0 & 152.4 & 175.0 \\
\hline Plug flow fraction & 0.070 & 0.065 & 0.20 \\
\hline
\end{tabular}
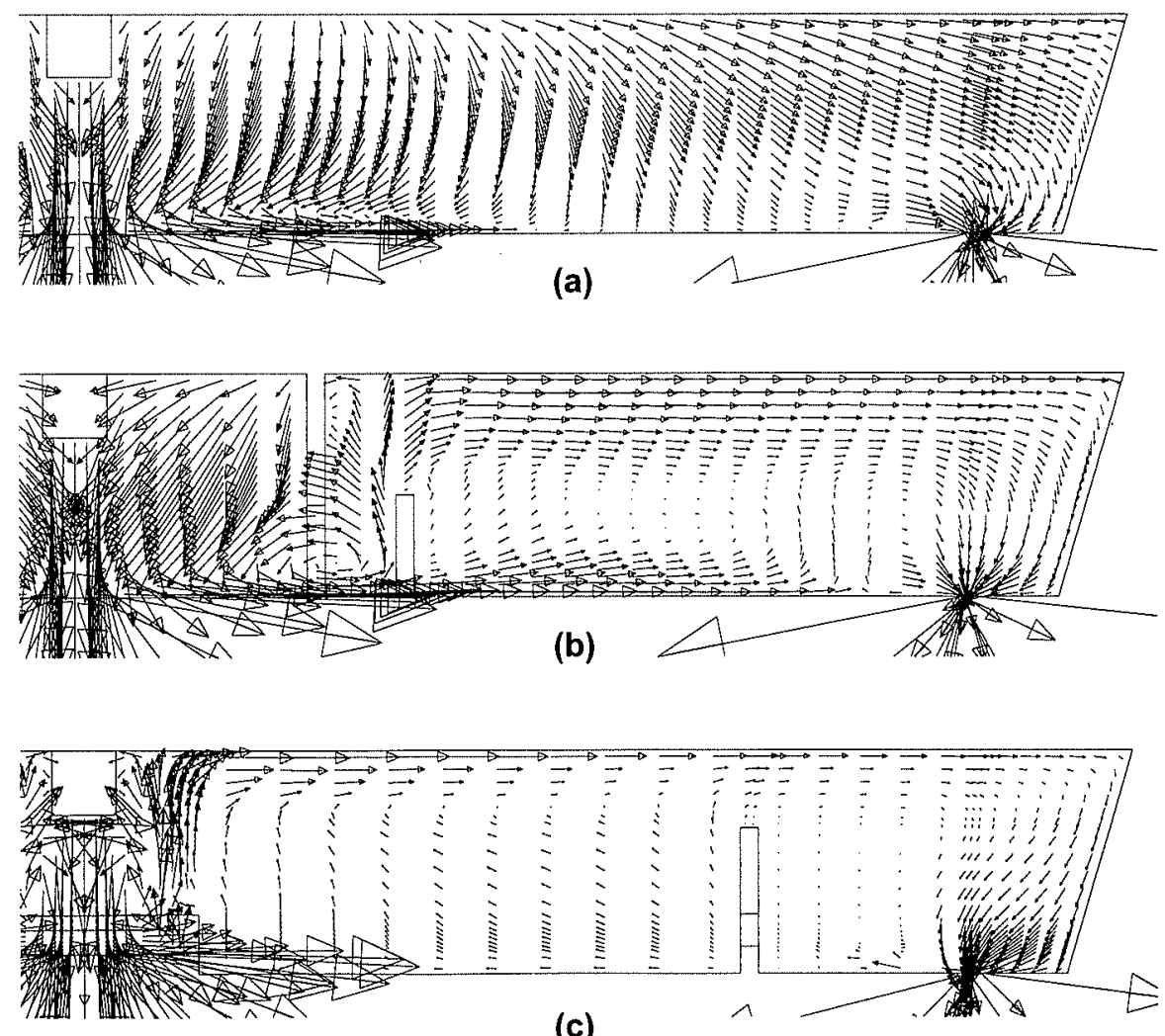

(c)

Fig. 6. Velocity profiles of liquid steel in tundishes receiving steel at a constant temperature of $1840 \mathrm{~K}$. 

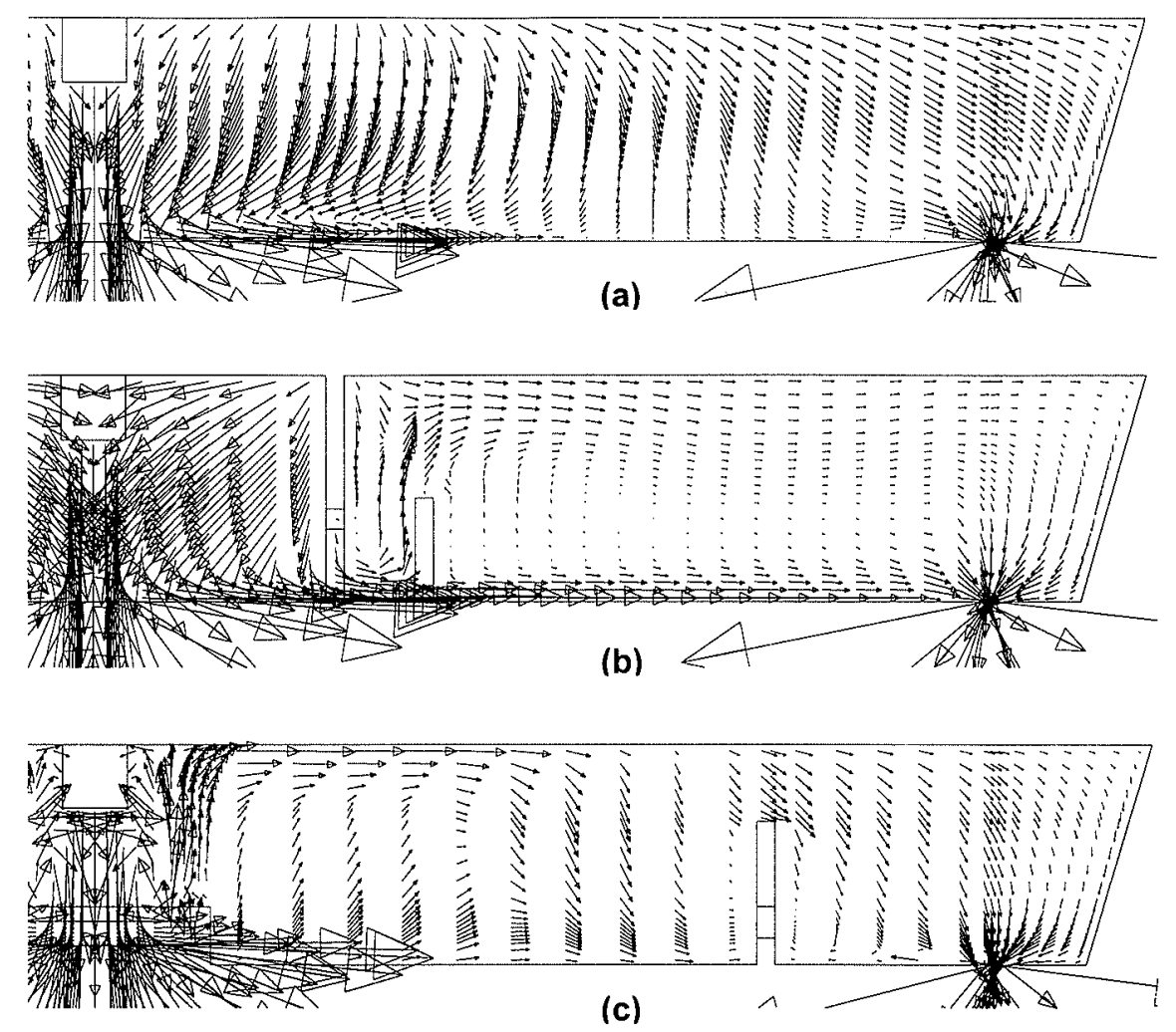

Fig. 7. Velocity profiles of liquid steel in tundishes $I$ min after a step input temperature of cold steel at $1825 \mathrm{~K}$ was fed.

(see Fig. 2). This in agreement with the water model predictions (see Fig. 5). This affects negatively the performance of this tundish as a reactor.

On the other hand, in the tundish with TI\&B the steel flows upstream just in the entering zone thanks to the effects of the TI. High fluid velocities are concentrated in the core of the incoming stream jet but the fluid exiting from the TI shows rather low velocities decreasing, as a consequence, surface splashing and turbulence.

Unsteady state conditions one minute after starting a step input of cold steel at $1825 \mathrm{~K}$ are presented in Figs. 7(a), 7(b) and 7(c) for a bare tundish and the tundish with arrangements $\mathrm{W} \& \mathrm{~B}$ and TI\&B respectively. Fluid flow patterns in the three cases suffer radical changes in comparison to the steady state conditions already described in Fig. 6. for a bare tundish (Fig. 6(a)) fluid flow pattern near the entering stream jet is similar to the steady state case because the effects of inertial forces exceed flotation forces. However, outside the influence of the entering stream fluid velocities are decreased, in relation to the steady state, and more oriented toward the tundish bottom.

Now comparing Figs. 6(b) and 7(b) for a tundish with a W\&B arrangement it is clearly apparent an increase of the bypass-flow since cold steel tends to flow more eagerly near the tundish bottom.

The influence of an arrangement TI\&B is presented in Fig. 7(c), which should be compared with Fig. 6(c). Velocity vectors are oriented toward the tundish bottom due to the higher density of cold steel. However, the presence of a baffle drives upward the cold steel avoiding the formation of any bypass-flow.

Effects of flotation forces on fluid flow are also evident when a step-input temperature of $1855 \mathrm{~K}$ is introduced in the system. The corresponding fluid flow patterns for a bare tundish, and the tundish with W\&B and TI\&B arrangements are presented in Figs. 8(a), 8(b) and 8(c) respectively. Now comparing these Figures with Figs. 6 and 7 considerable changes on flow patterns are also clearly seen in this case. For a bare tundish steel velocities near the surface are considerably higher in comparison to the steady state and cold feeding cases. Flotation forces drive strongly the fluid toward the free surface forming a heavy recirculating flow near the outlet.

Steel flow with the W\&B arrangement (Fig. $8(\mathrm{~b})$ ) is quite complex. Although, it remains essentially the same in the stream entering zone and the W\&B zone, since as in the cold steel case inertial forces are higher than flotation ones.

Finally steel flow pattern in a tundish with a TI\&B arrangement is shown in Fig. 8(c). Flow vectors in or near the surface are larger than in the two precedent cases. Here the fluid is driven by the combined effect of the TI and the flotation forces. A large recirculating flow is predicted in most of the symmetric plane.

\subsubsection{Heat Transfer}

Temperature profiles in the symmetric plane after one minute that the step input of cold or hot steel was introduced are shown in Figs. $\mathbf{9}$ and $\mathbf{1 0}$ respectively for the three cases already mentioned. In the case of cold steel the bare tundish, Fig. 9(a), shows progressive 

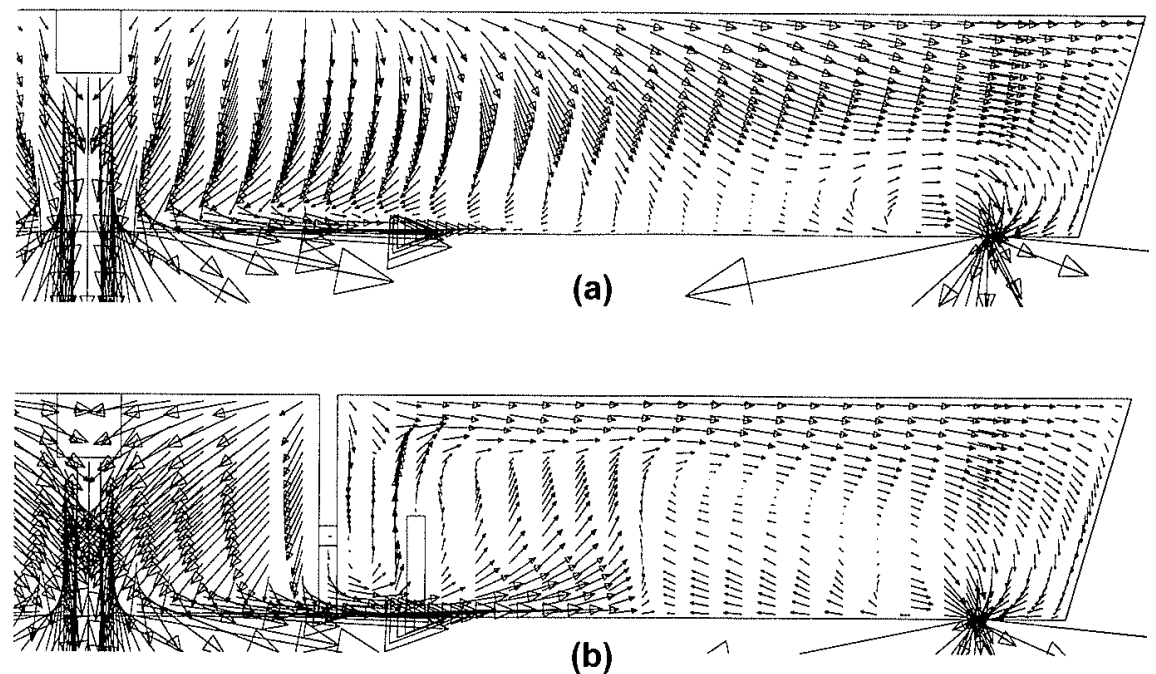

(b)

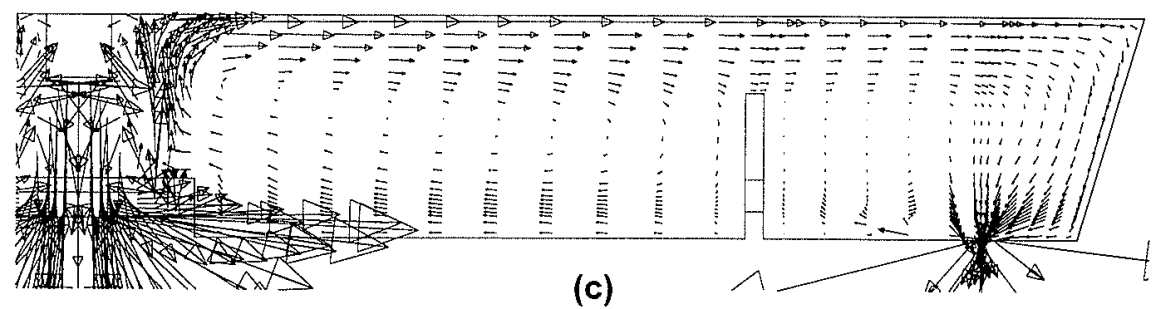

Fig. 8. Velocity profiles of liquid steel in tundishes 1 min after a step input of hot steel at $1855 \mathrm{~K}$ was fed.

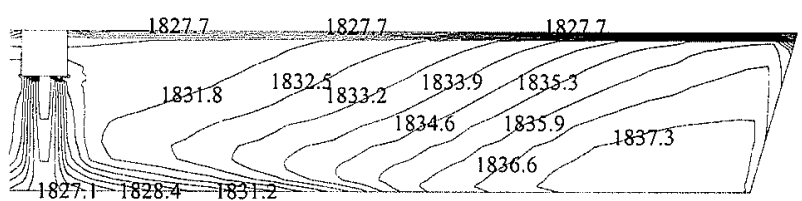

(a)

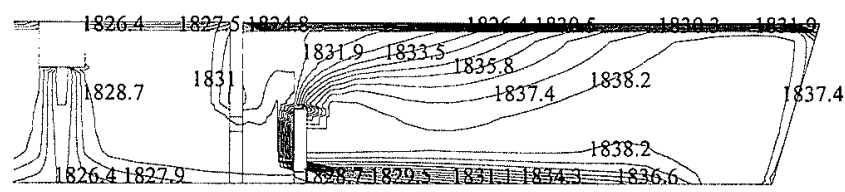

(b)

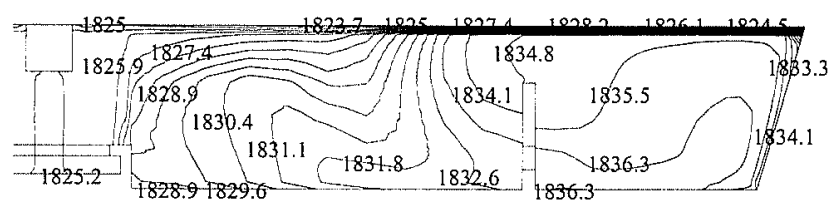

(c)

Fig. 9. Temperature profiles of liquid steel in tundishes 1 min after a step input temperature of cold steel at $1825 \mathrm{~K}$ was fed.

temperature decreases downstream while the tundish with a W\&B arrangement renders temperature stratification. Besides, coldest steel is flowing along the tundish bottom, Fig. 9(b), a fact that is in agreement with the bypass flow observed in Fig. 7(b). A tundish with a TI\&B arrangement, Fig. 9(c), yields also thermal stratification although in a more distributed pattern in comparison

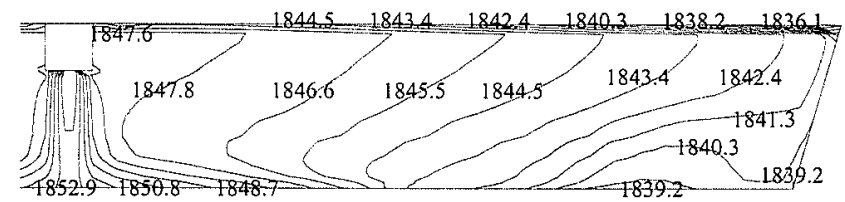

(a)

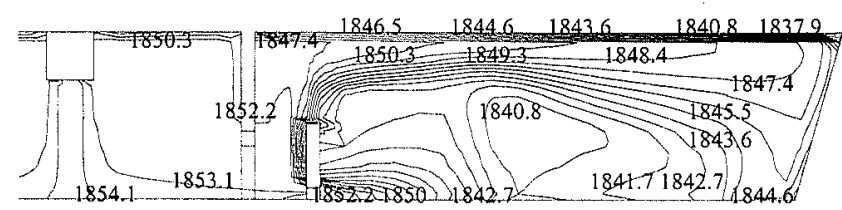

(b)

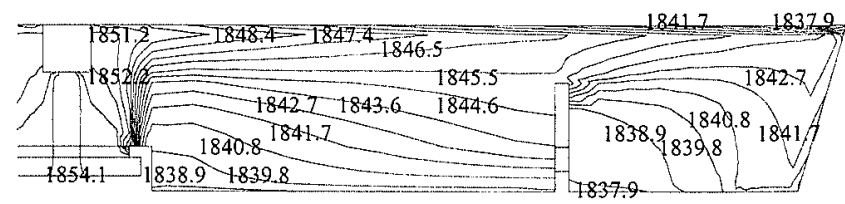

(c)

Fig. 10. Temperature profiles of liquid steel in tundishes $1 \mathrm{~min}$ after a step input temperature of hot steel at $1855 \mathrm{~K}$ was fed.

with the previous case.

Step input of hot steel for a bare tundish is shown in Fig. 10(a) where it is seen a similar trend as in the case of cold steel, that is, temperature decreases progressively downstream. For a tundish with a W\&B arrangement thermal stratification is again observed but now temperature profiles take loop like shapes owing to the 


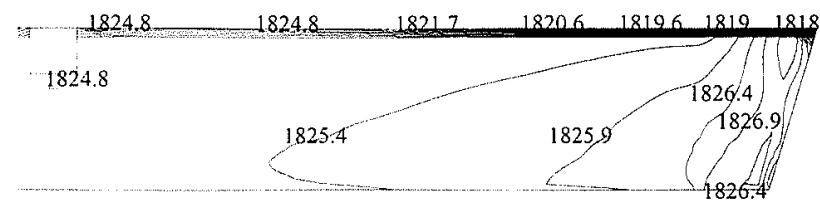

(a)

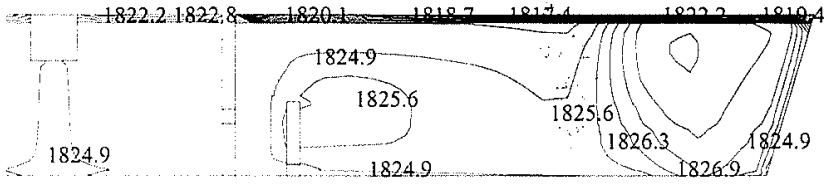

(b)

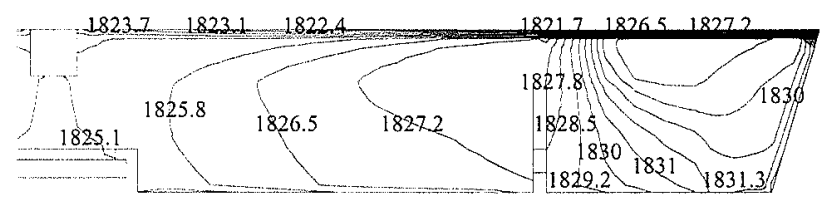

(c)

Fig. 11. Temperature profiles of liquid steel in tundishes 4 min after a step input of cold steel at $1825 \mathrm{~K}$ was red.

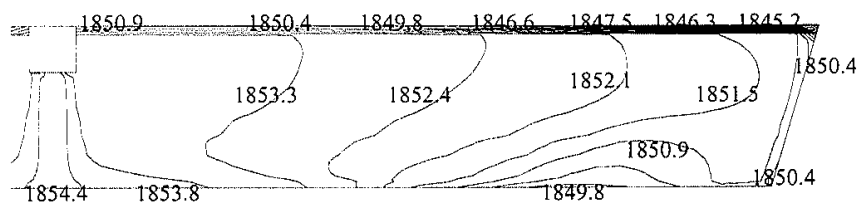

(a)

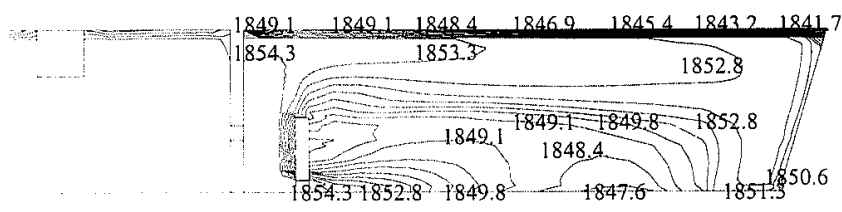

(b)

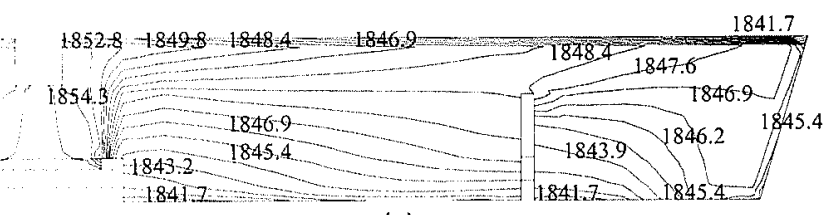

(c)

Fig. 12. Temperature profiles of liquid steel in tundishes 4 min after a step input of hot steel at $1855 \mathrm{~K}$ was fed.

flotation forces which promote complex counter-flows as seen in Fig. 8(b). Fig. 10(c) shows the temperature profile for a tundish with a TI\&B arrangement. The TI promotes also an upper side oriented temperature profile.

Temperature profiles in the symmetric plane at longer times, for example, after four minutes that a step input of cold or hot steel has been introduced are shown in Figs. 11 and 12 respectively.

In all cases, up to here discussed, there are very steep temperature gradients near the bath surface because of the high heat losses by radiation mechanisms to the environment. Another point worthy to be mentioned is that temperatures, at long times after performing a step input of cold or hot steel, in the neighborhoods of the
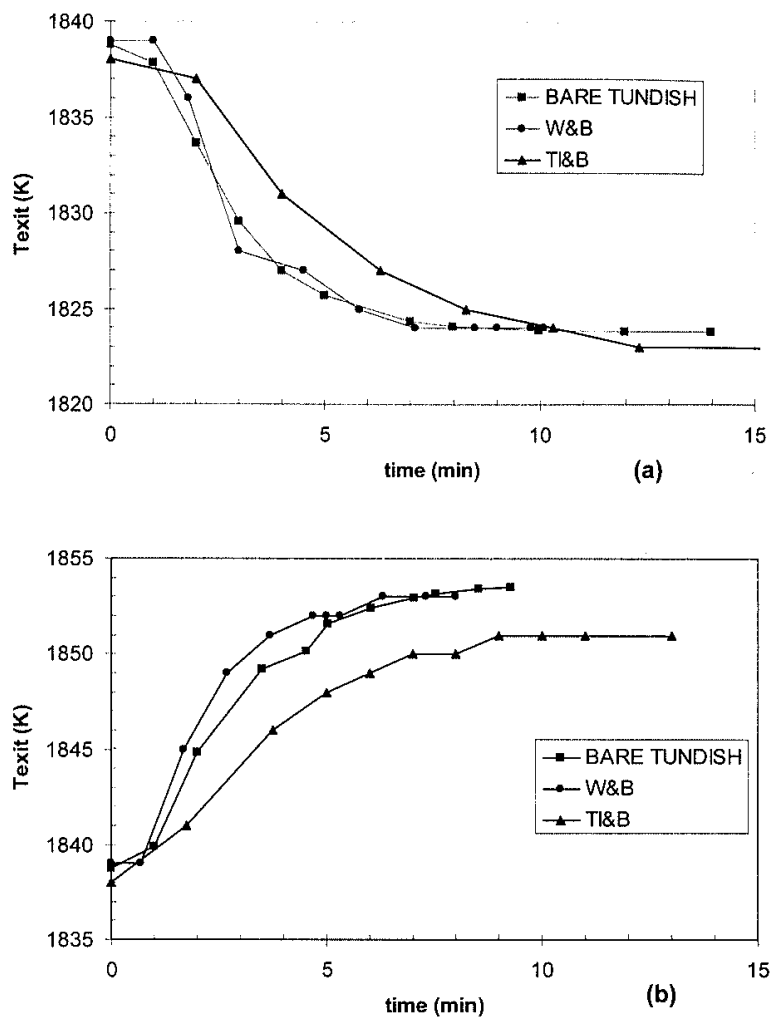

Fig. 13. Dynamic behaviors of output temperatures from tundishes when steps input temperatures are introduced into the system. (a) Step input of cold steel. (b) Step input of hot steel.

outlet nozzle are similar between the bare tundish and the tundish with a W\&B arrangement. And it is different in the TI\&B arrangement.

From these later observations it is inferred that the TI\&B arrangement has a kind of damping effect on temperature changes of the incoming steel. Just to visualize better this apparent behavior steel temperatures in the outlet nozzle were plotted against casting time for the two FCD arrangements and the bare tundish under cold steel and hot steel feeding conditions. These results are plotted in Figs. 13(a) and 13(b) for cold steel feeding and hot steel feeding respectively.

In these Figures the initial temperatures, at time zero for the three cases, are slightly lower than $1840 \mathrm{~K}$ which is the steel incoming temperature under steady state conditions. These effects are a consequence of heat losses through the bottom and walls of the tundish as well from the free surface of the bath. Evidently, these initial temperatures depend on the design of a given FCD arrangement.

For a step input of cold steel, Fig. 13(a), the dynamics of the thermal behavior is very similar for the bare tundish and the tundish with a W\&B arrangement even for long times such as $16 \mathrm{~min}$. At this time, difference in output temperatures between all three cases is about $1 \mathrm{~K}$, which, in practical terms, is meaningless. Meanwhile the decrease rate of steel output temperature for the tundish with a TI\&B arrangement is slower than the two previous cases indicating that has a dampening effect on sudden changes of lower incoming steel temperature. Additionally, in the case of hot steel feeding the bare tundish 
and the tundish with a $\mathrm{W} \& \mathrm{~B}$ arrangement yield increasing temperature rates which are, generally, also similar. This is not the case for the TI\&B arrangement, Fig. 13(b), where rising rate of temperature is slower than the bare tundish and the tundish with a W\&B arrangement. According with this discussion it is foreseeable that during a normal, steady state casting operation, where temperature changes of the feeding steel are softer, the TI\& $\mathrm{B}$ arrangement will moderate and delay the effects on the steel output temperature. On the same line, during ladle changes, this arrangement will allow to keep under narrower band temperature variations in the outlet nozzle.

Thus the benefits of using a TI\&B arrangement in this tundish are not only related with improvements in steel cleanliness, less steel splashing and less pickup of gases ${ }^{9}$ ) but also with a better control of steel output temperature.

\section{Conclusion}

Two arrangements of FCD in a tundish consisting the first one in a pair of weirs and a pair of baffles (W\&B) and the second one in a turbulence inhibitor and a pair of baffles (TI\&B) were water and numerically simulated. The fluid flow and thermal performances of both arrangements were also compared with a bare tundish. The conclusions reached in this study are as follows:

(1) According to the water model, the TI\&B arrangement was more effective to eliminate surface turbulence and disturbs allowing a softer fluid flow than the $\mathrm{W} \& \mathrm{~B}$ and bare tundish cases.

(2) The TI\&B arrangement yielded the highest plug-flow/dead-volume ratio among the three cases examined.

(3) Flotation forces affect fluid flow patterns of liquid steel under non-isothermal conditions.

(4) The TI\&B arrangement, in this tundish, helps to mitigate the effects of temperature changes of the incoming steel by giving slower output response to thermal disturbs.

(5) As a consequence of the precedent conclusion thermal mixings in a bare tundish and another one equipped with a W\&B arrangement are very similar and both are different to that corresponding to a tundish with a TI\&B arrangement.

\section{Acknowledgments}

The authors acknowledge to FOSECO Inc. a permission to publish this paper. Also the authors (RDM, SLR and JPR) give the thanks to the institutions SIN, CoNaCyT and DEPI for their important support to the Process Metallurgy Group at IPN.

\section{REFERENCES}

1) R. Ahuja and Y. Sahai: Proc. 24th Annual Conf. of Metallurgists, CIM, Canada, (1985), 73.

2) J. Tsukobura, I. D. Sommerville and A. McLean: 24th Annual Conf, of Metallurgists, CIM, Canada, (1985), 124.

3) H. E. Youduo and Y. Sahai: Acta Metall. Sin., 2 (1988), 93.

4) J. Szekely, O. J. Ilegbusi and N. El-Kaddah: Phys. Chem. Hydrod., 9 (1987), 453

5) S. Joo and R. I. L. Guthrie: Metall. Trans., 24B (1993), 755.

6) K. H. Tacke and J. C. Ludwig: Steel Res., 58 (1987), 262.

7) P. Rasmussen: Proc. 77th Steelmaking Conf., Iron and Steel Soc., Warrendale, PA, (1994), 219.

8) D. Bolger and K. Saylor: 77th Steelmaking Conf., Iron and Steel Soc., Warrendale, PA, (1994), 225.

9) R. D. Morales, J. Palafox-Ramos, S. Lopez-Ramirez, M. A. Dominguez-Crespo, C. Rincon, D. Salazar and A. Dainton: Proc. 81st Steelmaking Conf., Iron and Steel Soc., Warrendale, PA, (1998), 325.

10) L. J. Heaslip, I. D. Sommerville and A. McLean: Continuous Casting, 1, Chemical and Physical Interactions during Transfer Operations, Iron and Steel Soc., Warrendale PA, (1983), 67.

11) H. S. Fogler: Elements of Chemical Reaction Engineering, Prentice Hall Int., U.K., (1992), 708.

12) D. B. Spalding: Int. J. Num. Math. Eng., 4 (1972), 551.

13) D. A. Anderson: Computational Fluid Mechanics, McGraw Hill, New York, (1984), 221.

14) J. Szekely: Fluid Flow Phenomena in Metals Processing, Academic Press, New York, (1979), 124.

15) J. De J. Barreto-Sandoval, M. A. Barron-Meza and R. D Morales: ISIJ Int., 36 (1996), 543.

16) R. I. Issa: J. of Computational Physics, 62 (1985), 40.

17) R. I. Issa, A. Befrui, K. R. Beshay and A. D. Gosman: J. of Computational Physics, 93 (1991), 388. 